\section{AVES, CERDOS, VACAS Y OTRAS LOCURAS. POSHUMANISMO Y TECNOCIENCIA}

\author{
Eugenio Moya \\ Universidad de Murcia \\ emoya@um.es
}

Cómo citar este artículo/ Citation: Moya, E. (2013). "Aves, cerdos, vacas y otras locuras. Poshumanismo y tecnociencia". Arbor, 189 (762): a056. doi: http://dx.doi.org/10.3989/ arbor.2013.762n4007

Recibido: 30 noviembre 2012. Aceptado: 21 mayo 2013.

RESUMEN: A la luz de la fenomenología de la vida de Kant y Jonas, el autor defiende una necesaria ética de la especie humana y problematiza los principios de un emergente movimiento filosófico: el Transhumanismo, que defiende las oportunidades tecnológicas de rediseñar la condición humana, de aumentar de las capacidades intelectuales, físicas y emocionales de la humanidad y de liberarnos del confinamiento en el planeta Tierra.

PALABRAS CLAVE: autoorganización; Jonas; Kant; libertad; riesgo; tecnociencia; Transhumanismo; vida.

\section{BIRDS, PIGS, COWS AND OTHER MADNESSES. POST-HUMANISM AND TECHNOSCIENCE}

Copyright: @ 2013 CSIC. Este es un artículo de acceso abierto distribuido bajo los términos de la licencia Creative Commons Attribution-Non Commercial (by-nc) Spain 3.0.

ABSTRACT: Against the backdrop of the Kantian and Jonasian phenomenology of life, the author argues for an ethics of the human species and highlights the issues surrounding the principles of an emergent school of speculative philosophy, namely Transhumanism, which champions our technological opportunities to redesign the human condition, to enhance our intellectual, physical and emotional capacities, and to free us from our confinement on planet earth.

KEYWORDS: self-organisation; freedom; Kant; Jonas; life; risk; technoscience; Transhumanism. 


\section{EVOLUCIÓN, COMPLEJIDAD Y AUTOORGANIZACIÓN}

Somos un producto de la bioevolución. También de la cosmoevolución. Hay una continuidad entre physis, bios y anthropos. No tiene sentido, pues, considerarnos un reino, el humano, dentro de otro: el natural. Sin embargo, a pesar de que las presentaciones habituales miran a la Modernidad para encontrar el origen de la tesis del doble reino, fue, paradójicamente, Kant, el culmen del pensamiento moderno, quien defendió, desde una visión inmanentista, sistémica y dinámica de la naturaleza, una escala gradual continua de criaturas [kontinuierlichen Stufenleiter der Geschöpfe]; esto es, un proceso en el que las transiciones desde los minerales a los vegetales, y de éstos a los animales y al mismo hombre no pueden ser vistos más que como un constante aumento de complejidad y autoorganización.

Cosmogénesis (emergencia de formaciones materiales: sistemas solares, planetas, cuerpos físicos y demás) y filogénesis (formación de seres vivos, organizados y autoorganizados), seguirían un mismo esquema. Más aún: a él responde hasta la misma génesis de la autonomía cognitiva y moral de las naturalezas racionales ${ }^{1}$. Desde su temprano ensayo sobre la Historia General de la Naturaleza, Kant no deja lugar a otra interpretación:

"Las mismas leyes generales del movimiento que han indicado a los planetas superiores un lugar más alejado del centro de atracción y gravedad en el sistema del mundo, los ha colocado al mismo tiempo en la condición más ventajosa para realizar sus formaciones en el mayor alejamiento del punto de relación de la materia burda [der groben Materie] y además con más libertad." ${ }^{2}$

En Sueños de un visionario escribe, incluso, que la creciente autoorganización y autonomía alcanza al ser sintiente de los animales y a todo lo que en el mundo encierra un principio de vida, pues todo ser vivo "está en condiciones de determinarse y modificarse por sí mismo" ${ }^{3}$. No se trata, en cualquier caso, de conjeturas que abandonara en el periodo crítico ${ }^{4}$. En la Crítica del Juicio afirma que, a partir de los datos aportados por la anatomía comparada y la historia natural, el arqueólogo de la naturaleza siempre tiene razones para conjeturar un proceso evolutivo (involutivo, diría $\mathrm{Kant}^{5}$ ) de las especies o formas. Habla de la naturaleza como de una gemeinschaftlichen Urmutter, de cuyo seno, en virtud de su fuerza formativa [Bildungskraft], han brotado hasta su osificación todas las especies existentes, que, a su vez, por mor de su autoorganiza- ción y disposiciones internas, generan los demás seres de su linaje natural ${ }^{6}$. Siguiendo la estela de los naturalistas franceses, Kant introduce, así, como hipótesis la idea de un origen o ancestro común (Abstammung), de todas las especies, que manejará posteriormente Darwin. La coincidencia de tantas especies, la analogía de formas, refuerza, dice el de Königsberg,

"la conjetura de un genuino parentesco [Verwandschaft] de las mismas; desde aquella en la que el principio de los fines parece hallarse sumamente acreditado, o sea el hombre, hasta el pólipo, e incluso desde este hasta, finalmente, alcanzar la escala inferior que podemos observar de la naturaleza: la materia bruta, de cuyas fuerzas, según leyes mecánicas (iguales que las que siguen la producción de los cristales), parece provenir toda la técnica de la Naturaleza, una técnica que en los seres organizados nos es tan incomprensible que nos creemos obligados a pensar para ellos otro principio." ${ }^{7}$

Y es que, como escribe en el $\S 65$ de la Crítica del Juicio, la naturaleza es productora, y produce siguiendo esquemas, esto es, siguiendo el mismo modelo, pero no es insensible al contexto o circunstancias de su propia historia:

\begin{abstract}
"La naturaleza se organiza más bien a sí misma y en cada especie de sus productos organizados siguiendo globalmente un mismo modelo, pero también con las oportunas divergencias que exige la propia conservación, según las circunstancias." ${ }^{8}$
\end{abstract}

La misma idea de comunidad moral tiene ese mismo fundamento natural. La idea con la que coquetea en los Träume es la de explicar las disposiciones morales del ser humano apelando a la gravitación newtoniana; sin embargo, no deja de ser un recurso retórico contra los espiritualistas. Sus observaciones y reflexiones sobre la evolución general de la naturaleza no le condujeron nunca a la negación de la libertad. Ésta es un Faktum. En la Crítica del Juicio escribe:

“Opinar que en el universo material hay espíritus puros y sin cuerpos capaces de pensar (...) equivale a fantasear y no es en absoluto cosa de opinión, sino una simple idea; lo que resta cuando se sustrae todo lo material de un ser pensante y, sin embargo, se le sigue dejando el pensar... Pero hay algo muy notable: entre los hechos se encuentra incluso una idea de la razón (idea que en sí no es susceptible de exhibición alguna en la intuición y cuya posibilidad, por tanto, tampoco es susceptible de ninguna prueba teórica), y ésta es la libertad." ${ }^{\prime 9}$ 
Su admisión tampoco le condujo a postular un hiato ontológico en la naturaleza, esto es, reconocerle al ser humano una naturaleza y fundamento diferente al de todos los demás seres naturales. La emergencia de la libertad encuentra su fundamento óntico en esa tendencia de la naturaleza a ganar complejidad y autoorganización. No en vano la Naturaleza es autopoyética. Las leyes morales, por eso, encuentran su necesidad y universalidad, como las mismas leyes generales de la naturaleza, que prescribe el entendimiento, en su $a$ prioricidad; esto es, su fundamento no se da al margen de las condiciones físico-químicas del Universo, y tampoco de las disposiciones de la naturaleza animal que posee el ser humano. En la conclusión de la Crítica de la razón práctica lo indica, pero es aún más claro en la Fundamentación de la metafísica de las costumbres. En efecto, una vez planteada la idea del valor absoluto de la buena voluntad humana, se apresura a afirmar, frente a posibles malentendidos, que la oposición naturaleza-libertad, es aparente, pues nuestra razón no deja de ser, al mismo tiempo que una institución de la naturaleza ${ }^{10}$, una Naturabsicht -una intención de la misma ${ }^{11}$.

Podríamos decir que el principio básico de la ciencia: el mundo físico está cerrado causalmente, que hace suyo el criticismo kantiano, no le conduce a apoyar el determinismo, porque siempre considera que la misma evolución de ese mundo mecánico hacia mayores niveles de complejidad y apertura hizo emerger un mundo biológico y un mundo humano, que, aunque irreductibles a aquél, no son independientes entre sí. En términos antropológicos: aunque no se pueda negar que el hombre sea un animal y, por tanto, una parte más de la naturaleza, no puede mantenerse que no haya lugar en él para la libertad ${ }^{12}$.

Aunque las concepciones morales de Kant son, en cierto modo, antropocéntricas, yerran quienes amparándose en textos como los del Comienzo presunto de la historia humana (en los que Kant habla - recordando el Génesis, V. 22- de las criaturas como medios e instrumentos entregados a la voluntad humana ${ }^{13}$ ), tratan de extraer conclusiones para toda su filosofía de la naturaleza. Olvidan lo que el mismo Kant en esos fragmentos señala: que a las presunciones no les es lícito enaltecer sus pretensiones y han de concebirse como simples juegos de la imaginación; como conjeturas.

Desde el punto de vista objetivo, la naturaleza no dispone unas cosas para otras. Ni tan siquiera las demás cosas para el ser humano ${ }^{14}$. $\mathrm{Y}$ si es verdad que sólo a éste (en cuanto persona), desde una perspectiva suprasensible, le atribuye, en principio, relevancia moral y, por ende, dignidad, desde el punto de vista fenoménico es tan irrelevante -o tan relevantecomo cualquier otro $\operatorname{ser}^{15}$. Cualquier rasgo de antropocentrismo o especismo está de más. Kant, de hecho, va más allá de los naturalistas franceses del XVII y XVIII; por ejemplo, de Buffon:

"Por muy teleológicamente ordenadas que ahora puedan parecer la configuración, la estructura y el declive de las tierras para recorrer las aguas pluviales, los manantiales subterráneos entre diversas capas geológicas (para varios productos) y el curso de los torrentes, un examen más detallado de todo ello demuestra, sin embargo, que se han originado como efecto en parte de erupciones volcánicas, en parte del agua, también como efecto de inundaciones y emergencias oceánicas, tanto en lo que atañe a la primera génesis como sobre todo lo que hace a esa ulterior transformación que llevó aparejado el ocaso de sus primeras producciones orgánicas. Ahora bien, si el hábitat, el seno maternal (de la tierra y del mar) para todas esas criaturas no indica sino un mecanismo carente por completo de propósito en su producción, ¿cómo y con qué derecho podemos reclamar y afirmar para estos productos un origen distinto? Y aunque el examen más minucioso de aquellas devastaciones parece probar, a juicio de Camper que el hombre no estaba comprendido en esas revoluciones, es sin embargo, tan dependiente del resto de las criaturas terrestres que, si se admite un mecanismo de la naturaleza que impere universalmente sobre las restantes, el hombre ha de considerarse como comprendido bajo dicho mecanismo, aun cuando su entendimiento haya podido salvarle de sus devastaciones (al menos en gran parte)."16

Las distancias con Forster o Herder son también en este punto insalvables. Para Kant, pensar en una sabiduría y preordenación del mundo que explicara el especial cuidado [Vorsorge, Fürsorge] que la naturaleza ha tenido con el hombre - como habitante de la Tierra - otorgándole las demás cosas como medios de subsistencia, presupone que los hombres debían vivir sobre la Tierra o determinadas zonas ${ }^{17}$, pero tal presunción es excesiva:

"En los países fríos la nieve preserva las simientes de las heladas; facilita la comunidad de los hombres (gracias a los trineos); el lapón encuentra en ella animales, como los renos, que propician esa comunidad; los cuales encuentran el alimento suficiente en el musgo que ellos mismos escarban bajo la nieve... Aquí parece darse una admirable convergencia de tantas relaciones en la naturaleza para un fin: el groenlandés, el lapón... Pero no se ve por 
qué deben vivir hombres allí. Decir que en vistas a ello los vapores caen del aire en forma de nieve o el mar tiene sus corrientes que acarrean hacia allí la madera crecida en países más cálidos (...), supondrá un juicio tan osado como arbitrario."18

Las migraciones, las luchas entre los hombres, las catástrofes y devastaciones avalarían, más bien, las hipótesis de la omnisuficiencia [Allgenugsamkeit] del ser humano y de fuerzas naturales que trabajan en estado caótico, dos hipótesis que impiden ver su historia sobre la Tierra como un mero teatro de la sabiduría divina ${ }^{19}$. Las circunstancias o contingencias naturales, sociales y culturales son para el epigenetismo kantiano decisivas. Le es posible pensar, incluso, en futuras modificaciones sustanciales de los caracteres. En la misma Crítica de la razón pura (A 779 / B 807) escribe Kant:

"El carácter contingente de las generaciones, que depende tanto en el hombre como en las criaturas irracionales de las circunstancias y también, a menudo, de la nutrición, del modo de vida, de sus veleidades y antojos e incluso del vicio, representa una importante dificultad contra la opinión que sostiene la eterna perduración de una criatura cuya vida ha comenzado en circunstancias tan insignificantes y tan por entero dejadas en manos de nuestra libertad. En cuanto a la continuidad de la especie como tal (aquí, en la Tierra), esta dificultad carece de importancia, ya que lo contingente en un caso se halla sometido de todos modos a una regla general".

La atención a los cambios drásticos en las circunstancias, que señalaban los naturalistas de su tiempo, llevaron incluso a Kant a sostener que en el proceso evolutivo podían diferenciarse épocas distintas y a aventurar que no hay motivo alguno para suponer que no acontecerán otras:

"en las que un orangután o un chimpancé diese a los órganos que sirven para marchar, para tocar los objetos y para hablar, una estructura humana, cuyo interior encerrase un órgano para el empleo del entendimiento y se desarrollase paulatinamente por medio de la cultura social."

Sabemos, pues, antes incluso que desde Darwin, que el ser humano es el resultado - ni siquiera último- de un proceso natural donde el gran obrero es el tiempo y las contingencias [Zufälligkeiten]. Pero, entonces, si desde el punto de vista ontológico no es posible hacer los distingos morales entre personas y cosas, una cuestión resulta básica. La plantea Hottois cuando habla de solidaridad antropocósmica:
“El término solidaridad antropocósmica significa que el hombre no es esencialmente ajeno al cosmos que le rodea, sino por el contrario que es, en tanto que especie natural un producto de ese cosmos. (...) La solidaridad antropocósmica presenta también una implicación ética que podría resumirse de la forma siguiente. Si el hombre tiene valor y es resultado de una evolución y un medio naturales, éstos no pueden quedar totalmente fuera de valor y dignidad, so pena de defender la hipótesis de que lo específicamente humano procede de algo sobrenatural - una entidad espiritual, por ejemplo-. (...) Ciertamente, entre el valor del hombre y el de las formas de vida no humana pueden distinguirse grados, pero parece difícil, desde un reconocimiento ontológico de la solidaridad antropocósmica, negar a la Naturaleza todo valor en sí." 20

\section{VIDA Y PODER. LA APUESTA TRANSHUMANISTA POR LA TECNOCIENCIA}

Entre los seres que viven en la Tierra, tiene el ser humano, como animal rationabile, tres disposiciones naturales que lo singularizan del resto: su disposición técnica, su capacidad pragmática y la disposición moral. Nos interesa la primera, porque ella es una disposición natural (Naturanlage); y, segundo, porque por ella está capacitado el hombre para utilizar y manejar las otras cosas de acuerdo con sus intenciones ${ }^{21}$. Kant se aleja en el primer punto de Platón, quien, en el mito de Protágoras atribuyó un origen divino a la técnica humana. No; la técnica y sus productos son tan naturales como la habilidad de los pájaros a la hora de construir nidos o la de los topos para horadar el terreno.

Ortega y Gasset recurrió en 1951, en el Coloquio de Darmstadt, al estilo mitológico de Platón, pero a la orientación inmanentista kantiana. En "El mito del hombre allende de la técnica"22 pensó que la emergencia del primer humano debía ser imaginada como un proceso en el que un animal arbícola - que vivía sobre terrenos pantanosos, llenos de enfermedades epidémicas - enfermó $y$, aunque pudo sobrevivir, tuvo que existir con una hipertrofia cerebral. Se encontró súbitamente, así, con una enorme riqueza de figuras imaginarias, un mundo interior que no poseían el resto de sus antepasados; con lo que se vio condenado a habitar dos mundos, el interior y el exterior, permanentemente inadaptado y desequilibrado. El hombre es, por eso, un animal fantástico que, al extrañarse en la naturaleza, se ha visto obligado a inventar mundos, a forjar una técnica, para hacerse un lugar extranatural. Un auténtico monstruo natural técnicamente propicio. 
¿Decir técnica es, pues, decir libertad? Desde luego, tanto Kant como Ortega parecen apuntarlo. Nietzsche lo constata. Sin embargo, los matices son importantes. Según se nos dice en la Genealogía de la moral (III, 9), la técnica es lo propio del ser moderno, que se presenta como pura hybris [orgullo sacrílego] e impiedad. Es poder y consciencia de poder. Ella nos permite ir más allá de toda exigencia de autoconservación, en la dirección de una experiencia sin límites, una experimentación en la que "nosotros -escribe Nietzsche- hacemos experimentos que no nos permitiríamos con ningún animal". En el fondo, todos los complejos juegos que el asceta moral y el metafísico han sido capaces de jugar consigo mismo, siguen desenvolviéndose en la inventiva irreflexiva de técnicos $e$ ingenieros hasta tal punto que con el hombre se presenta sobre la Tierra un fenómeno inédito: un animal capaz de revolverse contra la naturaleza, contra sí mismo y, en definitiva, contra los intereses de su propia supervivencia"23: "Algo tan nuevo, profundo, inaudito, enigmático, contradictorio, y lleno de futuro, que con ello el aspecto de la Tierra se modificó de manera esencial". Un espectáculo demasiado delicado, maravilloso y paradójico,

"que despierta un interés, una tensión, una esperanza, casi una certeza, como si con él se anunciase algo, se preparase algo, como si el hombre no fuera una meta, sino sólo un camino, un episodio intermedio, un puente, una gran promesa ${ }^{24}$.

Reparemos en las últimas palabras de Nietzsche, porque hoy las ha hecho suyas un movimiento filosófico, cultural y político: el Transhumanismo, que retoma un nombre que J. Huxley empleó en New Bottles for New Wine (1957), para señalar que en un futuro cercano las especies humanas estarán en el umbral de un nuevo tipo de existencia.

La trascendencia y provocación de los principios de tal movimiento queda clara al leer el primer punto del Manifiesto de la World Transhumanist Association (1999), firmado, entre otros, por los profesores oxonienses Nick Bostrom, David Pearce, Max More y Anders Sandberg,

"Humanity will be radically changed by technology in the future. We foresee the feasibility of redesigning the human condition, including such parameters as the inevitability of aging, limitations on human and artificial intellects, unchosen psychology, suffering, and our confinement to the planet earth."

Frente al ludismo romántico de muchas posiciones filosóficas, los transhumanistas insisten en que la dignidad humana, incluso en su sentido moderno, consistió siempre más en lo que nosotros somos y lo que podemos llegar a ser, que en nuestra genealogía u origen causal. Para ellos, lo que nosotros somos no es solamente una función de nuestro ADN, sino también de nuestro desarrollo tecnológico y social. La naturaleza humana no puede concebirse, así, más que desde un punto de vista procesual y dinámico que no tiene por qué replicar y conservar exactamente la de nuestros antepasados del Pleistoceno. Los contextos (sobre todo tecnocientíficos y sociales) son diferentes. Podemos, pues, entrever una naturaleza y cultura poshumana, en la que resulten compatibles los conceptos de poshumanidad y dignidad. Es más, desde la perspectiva transhumanista, si no hay nada sacrosanto en la naturaleza humana, no debe concebirse diferencia alguna entre medios naturales y tecnológicos a la hora de desarrollar la vida humana, tanto en el medio interior como en el exterior. Enredarse en cuestiones de identidad, en lo que somos, implica, como señala Rail Kurzweil, olvidar la perspectiva materialista de lo que realmente hay en nosotros: una colección caótica de moléculas que constituyen cuerpo y cerebro ${ }^{25}$.

Tan natural o tan artificial como un panal de abejas es, pues, una central nuclear. Las dos expanden posibilidades ontológicas. Lo mismo que la nanotecnología y los nanomateriales pueden extender las capacidades humanas. Las asimetrías tradicionales no son más que impedimentos para el progreso (pos)humano ${ }^{26}$. Sloterdijk, en su famosa conferencia Normas para el parque humano (1999) contempla la misma posibilidad:

"Es el signo de los tiempos de la técnica y la antropotécnica que, cada vez más, los hombres van a parar por casualidad a la parte activa o subjetiva de la selección, incluso sin haber tenido que esforzarse intencionadamente por alcanzar el papel del seleccionador." ${ }^{27}$

El código de las antropotécnicas cambiaría el significado del humanismo clásico, pues con él se publicaría y registraría que la humanitas no sólo implica la amistad del hombre con el hombre, sino también -y de modo crecientemente explícito- que el ser humano representa el más alto poder para el ser humano. Frente a este hecho incontestable, frente a este destino, como diría Heidegger, nada puede hacer la vieja tradición cultural y literaria. Por eso, para él los próximos intervalos largos de tiempo habrán de ser para los hombres períodos de decisión sobre políticas de especie. 
En este contexto estaría justificada una relectura poshumanística de la obra de Nietzsche. Si el hombre es un efecto, para él, de programaciones y adiestramientos que pretenden inhibir su condición animal no hay obstáculo alguno para una mejora de la misma condición humana. De hecho, Nietzsche en el Anticristo encontramos la apuesta por una humanidad poshumana:

\begin{abstract}
“No qué reemplazará a la humanidad [...] es el problema que yo planteo [...]: sino qué tipo de hombres se debe criar, se debe querer como tipo más valioso, más digno de vivir, más seguro de futuro. Ese tipo más valioso ha existido ya con bastante frecuencia: pero como caso afortunado, como excepción, nunca algo querido voluntariamente. Antes bien, justo él ha sido lo más temido [...] y por temor se crió, se alcanzó el tipo opuesto: el animal doméstico, el animal de rebaño, el animal enfermo hombre [...] Yo llamo corrompido a un animal, a una especie, a un individuo cuando pierde sus instintos, cuando elige, cuando prefiere lo que a él le es perjudicial [...] La vida misma es para mí instinto de crecimiento, de duración, de acumulación de fuerzas, de poder: donde falta la voluntad de poder hay decadencia. Lo que yo asevero es que a todos los valores supremos de la humanidad les falta esa voluntad, que son valores de decadencia, valores nihilistas..." 28
\end{abstract}

Los sistemas morales y religiosos han perdido su influencia. De este modo el hombre ha quedado en el desamparo, a la intemperie. Como diría Camus, sólo oímos el silencio del mundo. El hombre, lo dijo también Sartre, está condenado a ser libre, a ejercer, esa faena poética de inventarse cada día a sí mismo.

En cualquier caso, Sloterdijk reconoce la aversión que suscita entre los humanistas el concepto de selección, crianza [Züchtung] o doma cuando se aplican a la esfera humana. Pero resulta evidente que el convencimiento de que los seres humanos son "animales bajo influjo" pertenece al credo del humanismo, así como el de que es imprescindible llegar a descubrir la técnica adecuada para su mejor guía o conducción. La etiqueta Humanismo recuerda - por ello, para Sloterdijk - la perpetua batalla en torno al hombre, que se ratifica como una lucha entre las tendencias bestializantes y las domesticadoras. Sólo puede entenderse el humanismo de Cicerón o Quintiliano si se lo concibe como toma de partido en una lucha entre los amigos de los libros y las lecturas humanizadoras y los defensores del anfiteatro, la ebriedad y las emociones arrebatadas. Por ello, ante el fracaso del humanismo literario para la selección de los mejores, Sloterdijk cree necesario explorar el camino de la biotecnología. Se pregunta qué podría haber de ilegítimo en esa unión de la preocupación educativa clásica con las potencialidades ofrecidas hoy por la tecnociencia. Las fantasías de selección biopolítica han tomado el relevo de las utopías de justicia, de ahí que Sloterdijk, al destacar los medios y posibilidades que ofrece la biotecnología, sugiera formular un código antropotécnico, dejando abierta la posibilidad a una antropotecnología en la que pueda cambiarse el fatalismo del nacimiento por un nacimiento opcional y una selección prenatal. Sustituiríamos, así, la idea humanista de perfectibilidad por la de autoinvestidura de la propia especie.

La distinción fenomenológica de Helmuth Plessner entre "cuerpo vivido o sido" (Leib) y "cuerpo dado o tenido" (Körper) adquiere, en este sentido, una sorprendente actualidad: se desvanece la frontera entre la naturaleza que "tenemos" y la dotación orgánica que nos "podemos dar". Se trata una facultad única en el reino animal que implicaría una indeterminación originaria que impide cualquier pretensión de fijación definitiva de su esencia. La antropología neokantiana de Plessner habla así de un carácter fundador (Urgrundcharakter) y a la vez sin fundamento (Ungrundcharakter) de la humanitas. Es ese carácter o posibilidad siempre abierta de ser-otro (Anders-sein) la que explota Sloterdijk ${ }^{29}$.

Hay que empezar a hablar, pues, de la superación definitiva del humanismo a favor de un enfoque poshumanista, un nuevo enfoque que sirva de respuesta filosófica a un mundo donde cada vez es más difícil distinguir entre lo natural y lo artificial, un nuevo enfoque que, frente al miedo a que lo artificial acabe sustituyendo a lo natural, reclama la necesidad de desarrollar un planteamiento que tenga en cuenta tanto lo humano como lo tecnológico. Un nuevo enfoque poshumanista que concibe la ingeniería genética y sus potencialidades domesticadoras como secuencias de un proceso de secularización postmetafísica.

No puede soslayarse - a pesar de lo que todavía hay de ciencia ficción - que estamos, como diría Nietzsche, ante un movimiento que, más allá de su interés filosófico, anuncia algo nuevo; quizás el paso de la bioevolución a la tecnoevolución ${ }^{30}$. Un tránsito que, quizás los transhumanistas, ven como un aumento de potencialidades, pero que no podemos dejar de ver muchos como arriesgado. Claro que los riesgos pueden, finalmente, querer ser corridos. Con lo que la cuestión fundamental debe ir más allá de cualquier cálculo estratégico y afectar a la misma condición de posibilidad de esos cálculos. Pero no adelantemos argumentos y conclusiones. Vayamos por partes. 


\section{TECNOCIENCIA, RIESGO Y RESPONSABILIDAD}

Basta leer la prensa diaria para percatarnos en las secciones de "Salud y cuidado" que, en gran parte por la ampliación del Estado social y la estabilización democrática de las instituciones, la biotecnología ha asumido, en los últimos quince años - gracias a sus innovaciones e investigaciones estrella: alimentos genéticamente modificados, Proyecto Genoma Humano, clonación...- gran parte del impulso de transformación social que ha perdido, como señalaba Sloterdijk, la política. Los ciudadanos ya no esperan que las leyes conduzcan a una nueva sociedad, pero son conscientes del potencial revolucionario de la ingeniería genética, las nanotecnologías, la medicina genómica o la bioinformática. Sin embargo, la percepción pública de ese potencial transformador va asociada a una creciente consciencia de los peligros asociados a las investigaciones e innovaciones tecnocientíficas. Y es que en las sociedades actuales la producción social de riqueza, el bienestar, va acompañado sistemáticamente por la producción social de riesgos. Ulrich Beck, que introdujo en 1986 el concepto de Risikogesellschaft para caracterizar la actual etapa de las sociedades avanzadas, lo señala con acierto:

\section{"Ios problemas y conflictos de reparto de la riqueza en la sociedad de la carencia son sustituidas por los problemas y conflictos que surgen de la produc- ción, definición y reparto de los riesgos producidos de manera científico-técnica." ${ }^{31}$}

Los últimos episodios mundiales de las vacas locas, la gripe aviar o la gripe porcina señalan claramente en ese sentido. Son riegos globales, construidos en entornos tecnocientíficos y ligados a procesos tecnoeconómicos de explotación de la naturaleza.

La historia del caso de las vacas locas - técnicamente de la encefalopatía espongiforme bovina (EEB) - es reveladora ${ }^{32}$. En septiembre de 1979 la Comisión Real de Medio Ambiente del Reino Unido, dirigida por Lord Zuckerman, fue requerida por el gobierno británico para evaluar una modificación en la elaboración de harinas animales para el engorde de vacuno, y elaboraba un informe epidemiológico en el que alertaba de que "el mayor problema de la utilización de desperdicios de animales en la fabricación de piensos es el riesgo de la transmisión de agentes patógenos a otros animales y posteriormente al hombre". A pesar de la claridad del informe y de los riesgos previsibles, en 1980 se modifica en Gran Bretaña, con el fin de reducir costes y mejorar el precio de las exportaciones, el sistema estadounidense "Carver-Greenfield" de fabricación de harinas de carne y huesos para la alimentación animal; se redujo tanto la temperatura de calentamiento $\left(133^{\circ} \mathrm{C}\right)$ como la duración (20 minutos a 3 bares de presión) de ese tratamiento de los despojos, cuando la tembladera de las ovejas era endémica en la cabaña británica y no había una eliminación garantizada del agente scrapie en cadáveres ovinos. El resultado fue que en 1982 surgen los primeros casos de bovinos afectados de EEB. Éstos presentaban síntomas parecidos a los ovinos enfermos de scrapie. En noviembre de 1986 la EEB es catalogada por el Laboratorio Veterinario Central del Reino Unido como síndrome específico. La intervención tecnocientífica había hecho de los rumiantes, naturalmente vegetarianos, unos animales carnívoros. Su alimentación fue más barata, pero el coste, al fin, fue desastroso, porque la existencia de un "agente infeccioso", como el prión permitió el salto interespecífico a través de la cadena alimentaria.

Otro tanto ha sucedido con el problema de la gripe porcina. La Organización Mundial de la Salud (OMS) ha registrado miles de casos de infección humana con el virus $A / H 1 N 1$. La fuente exacta del último brote, que extendió el miedo durante 2009 y 2010, sigue siendo incierta, aunque uno de los primeros casos - el de un niño de cinco años-, diagnosticado en la empobrecida comunidad de La Gloria, en el sudoriental estado mexicano de Veracruz, a 10 kilómetros de uno de los mayores criaderos de cerdos del mundo asocia la epidemia a las grandes industrias porcinas. Y es que lo que sabemos de la nueva gripe (un eufemismo para no dañar la industria cárnica) es que es una enfermedad infecciosa causada por cualquier virus perteneciente a la familia de Orthomyxoviridae y que ha resultado endémica en poblaciones porcinas. Esas cepas virales, conocidas como virus de la influenza porcina o SIV (por las siglas en inglés de Swine Influenza Viruses) han sido clasificadas en Influenzavirus $C$ o en alguno de los subtipos de los Influenzavirus $\mathrm{A}$, siendo los más conocidos los H1N1, H1N2, H3N1 y H3N2. Las personas que trabajan con aves de corral y con cerdos, especialmente en granjas industriales se hallan expuestas intensamente a este tipo de infecciones. Pero todavía más: se sabe que los cerdos, en condiciones de hacinamiento, debido al estrés, pueden contagiarse y ser portadores de virus de la gripe aviaria y de humanos, los cuales pueden combinarse (por ejemplo, intercambiando el genoma homólogo mediante reordenación genética de sub-unidades) con el virus H5N1, haciendo un traspaso de genes y favoreciendo la mutación en una nueva forma que transmisible entre humanos. En la investigación publicada en el Journal 
of Virology, en 1998 titulada "Bases moleculares para la generación en cerdos de virus de Influenza A con potencial pandémico" se advirtió ya de que:

“las observaciones biológicas y genéticas sugieren que los cerdos pueden servir como receptáculos de mezcla para la generación de influenza $A$, similar con aquellos responsables de las pandemias de 1957 y $1968^{\prime \prime 3}$

Una misma conclusión se publicaba en la revista Science en $2003^{34}$. En otro más reciente, publicado en Clinical Infectious Diseases se advertía, además, sobre la amenaza que suponen las porcinofactorías, concluyendo que:

"La exposición ocupacional a los cerdos incrementa en alta medida el riesgo de los trabajadores a la infección por influenza porcina. Los trabajadores de las granjas deben ser incluidos en estrategias de inmunización" 135

En el fondo, todos esos casos ilustran sobre algo que es común a los riesgos producidos en el seno de complejos sistemas tecnocientíficos: sobre ellos -en las fases iniciales de la evaluación - priman las incertidumbres causales; y los daños, a pesar de su sistematicidad e irreversibilidad, se sustraen a la percepción humana inmediata; esto es, sólo logran visibilidad en la misma investigación tecnocientífica. Los afectados pierden, así, una parte esencial de su soberanía cognitiva, con lo que los riesgos están sometidos de manera muy especial a los procesos sociales de definición: los medios y posiciones de la definición se convierten en posiciones sociopolíticas, económicas y epistemológicas claves. Como dice el mismo Beck, lo más interno - la decisión acerca de la verdad y el conocimiento- se desplaza por sus consecuencias hacia fuera; y lo externo - los riesgos globales - se convierte en un problema interno permanente del propio trabajo científico y su organización institucional ${ }^{36}$. Ahora bien, como señala Echeverría, analizando el caso de las nanotecnologías, resulta claro que "la racionalidad tecnocientífica tiene una importante base empresarial y la gestión del conocimiento y la innovación atiende ante todo a los riesgos económicos de dicha actividad, no a otro tipo de riesgos" ${ }^{\prime 3}$.

Con todo, como decíamos, resulta claro que la disposición a equilibrar costes y beneficios está implícita en la adopción misma del concepto de "riesgo". En su uso general, "riesgo" significa "posibilidad de daño", o un mal que se contrapone a un posible beneficio. Pero, ¿qué se hace con un riesgo? A veces, se decide correrlo. Es más, las regulaciones públicas sobre riesgos han asumido que no es posible, sino ex post, el control pleno de la actividad tecnocientífica, con lo que la intervención política siempre aparece cuando la apuesta ha salido mal. Por eso, la humanidad no puede encantarse sin más con el rediseño de su condición humana, con la posibilidad de extender sin límites sus capacidades intelectuales o con la aventura de acabar con el confinamiento terrestre. Ahora bien, los filósofos no podemos proponer que deba hacerlo con cálculos estratégicos, sino con argumentos, reflexivamente. Y la cuestión es la de si existen razones sustantivas (transcendentales, en sentido filosófico), pues de ellas - y no de sentimientos y actitudes - depende la cuestión de situarlos límites a nuestras decisiones e intervenciones tecnocientíficas.

Hans Jonas, a pesar de su pedagógica heurística del temor, es uno de los que ha intentado una argumentación filosófica sustantiva al apoyar su ética de la responsabilidad tanto en una fenomenología de la vida como en una filosofía del ser. Él mismo, en cualquier caso, reconoce que el enorme influjo de El principio de responsabilidad "no se debe, si no me equivoco, a su fundamentación filosófica, sino al sentimiento generalizado, del que ya entonces los observadores más atentos podían prescindir cada vez menos, de que algo podía ir mal para la humanidad"38.

Su punto de partida no es otro que la superación del hiato ontológico cartesiano -tradicionalmente gnóstico- entre "dentro" y "fuera"; entre subjetividad y objetividad. Los dos reinos de los que hablábamos al comienzo. La indagación de la vida orgánica ponía en evidencia, para él, que libertad y organismo son dos conceptos complementarios, inseparables, pues la primera denota un modo de ser que corresponde objetivamente (per se) a todo lo orgánico:

"la libertad es una característica ontológica fundamental de la vida como tal, y también, según resulta patente, el principio omnipresente de su progreso hacia niveles más altos." ${ }^{39}$

Jonas reconoce, como lo hizo Kant, el valor del hombre como voluntad libre, pero no cree que pueda diferenciarse entre ser y valor. La razón: si descendemos del nivel humano al de los animales, el principio de continuidad prescribirá que, aunque "lo representacional" desaparece alguna vez, lo apetitivo no desaparece nunca y éste es un signo de "subjetividad sin sujeto" germinal ${ }^{40}$. También de finalidad interna y de libertad (espontaneidad). De cualquier forma, lo que liga definitivamente al ser humano con toda la naturaleza orgánica es, para Jonas, el metabolismo [Stoffwechsel], ese 
intercambio sistémico entre un ser y los materiales del entorno, que es constitutivo de identidad, que hace que pierda sentido el dualismo "interno", "externo" y que hace que la Sorge, o cuidado del ser-ahí por ser, se convierta en una Vorsorge o preocupación porque el ser sea. Las cosas, como diría Ortega, dejan de ser tales para convertirse en importancias. En otras palabras, la libertad y creatividad humanas, su vocación tecnológica, no debería ir en contra de la naturaleza y ni tan siquiera del "mundo" que le ha dado y le da la posibilidad de ser:

"Así, hay «mundo» desde los primeros comienzos, y también desde el principio se da la condición fundamental de la experiencia: un horizonte, abierto por la mera trascendencia de la carencia, que amplía la clausura de la identidad interior a un entorno correlativo de relaciones vitales. Ese «tener mundo", esto es, la trascendencia de la vida, en la que esta necesariamente llega más allá de sí misma y amplía su ser en un horizonte, ya está dado tendencialmente en su indigencia orgánica de materia, una indigencia que por su parte está basada en la libertad formal de la vida respecto de la materia. De este modo, la dialéctica del hecho de la vida lleva de la positividad fundamental de la libertad ontológica (forma-materia) al factor negativo de la necesidad biológica (dependencia de la materia), y pasando por esta de nuevo a la positividad superior de la trascendencia, que reúne a los dos anteriores factores y en el que la libertad se apodera de la necesidad y la supera en virtud de la facultad de tener mundo. Con otras palabras, la autotrascendencia de la vida en dirección hacia el mundo, que en la sensibilidad conduce a tener presente un mundo, surge - con todas sus promesas de niveles más altos y más amplios de la antinomia primaria de libertad y necesidad que radica en el ser del organismo como tal." 41

Hay, pues, un elemento de trascendencia en toda existencia metabolizante en los que cualquier forma de vida se transciende constantemente con su propio mundo (Umwelt), de tal modo que este prolonga su ser, su espacio biológico y hace que el "aquí" se amplíe en el "alli" y el "ahora" en el "después".

Estamos, ciertamente, ante uno de los argumentos sustantivos, que ya había anticipado Kant en la Crítica del Juicio al acuñar, por primera vez, el concepto de "autoorganización"42.

"Puesto que el concepto de un ser organizado ya implica que es una materia en la que todo está en relación recíproca como medio y como fin; y esto sólo puede pensarse como sistema de causas finales, tenemos que concluir que al menos para la Razón humana sólo cabe una clase de explicación teleológica, no físico-mecánica, pues no puede indagarse en la física de dónde proviene originariamente toda organización." ${ }^{43}$

Ahora deberíamos apresurarnos a decir que si bien desde el punto de vista moral tienen sentido plantearse el asunto de si el ser humano constituye un fin final o un fin último, desde el punto de vista objetivo, desde el ámbito de una Lebenslehre sólo lo tiene hablar de fines internos, de teleonomía, y no de finalidad externa. Lo matiza el mismo Kant:

"La finalidad externa es un concepto totalmente distinto al de finalidad interna, la cual se halla vinculada con la posibilidad de un objeto al margen de si su propia realidad es o no un fin." ${ }^{44}$

Es evidente, que ya Kant entendía las limitaciones del concepto ontológico de sustancia para aprehender lo vivo -incluida la propia mente [Gemüt] - y, por ello, transita tanto en el plano biológico como en el psíquico a una concepción sistémica y dinámica para la que cualquier configuración orgánica posee una identidad autopoyética, resultado de la interacción con el entorno a partir de la ursprüngliche Stammbildung, esto es, de gérmenes y disposiciones originarias. De ahí, su idea de lo vivo como fin natural.

Convertido el medio - que no son sino otros seres- en una importancia, es evidente que la Sorge alcanza una dimensión no solamente moral, sino constitutiva. En este sentido, el nuevo modo de acción humana implicado en la tecnociencia contemporánea significa que es preciso considerar más dimensiones que la del interés de "el hombre". Hemos de llegar a la conclusión, incluso sin dejar de ser antropocéntricos morales, de que nuestro deber se extiende más lejos [del hombre] y que ha dejado de ser válida la limitación antropocéntrica de toda ética anterior. Podemos decir, que las fronteras de lo humano (personal) y lo in-humano empiezan a hacerse, anticartesianamente, borrosas ${ }^{45}$. Al menos ya no es un sinsentido preguntar si el estado de la naturaleza extrahumana -la bioesfera en su conjunto y en sus partes, que se encuentra ahora sometida a nuestro poder - nos exige, más allá de la moral, ontológicamente, porque con ella nos va "lo nuestro". Que el mundo sea, puede de hecho convertirse en un imperativo:

"La presencia del hombre en el mundo era un dato primero e incuestionable - escribe Jonas- del 
cual partía cualquier idea de obligación en el comportamiento humano. Ahora esa presencia misma se ha convertido en objeto de obligación: de la obligación de garantizar en el futuro la premisa primera de toda obligación, esto es, justamente la existencia de candidatos a un universo moral en el mundo físico." ${ }^{46}$

Más que una ética del medio ambiente necesitamos, como ha señalado Habermas una ética de la especie. Una ontología de la vida exige que el mundo sea, pero no que el mundo sea así. Manda ser para seguir siendo (Da-sein), pero no para seguir siendo así (So-sein). La ética de la especie manda, además, que el ser humano mantenga intactas aquellas condiciones esenciales, que lo han constituido como humano. Qué signifique esto, qué sea humanidad, podremos discutirlo, pero estará ligado indefectiblemente a "su mundo". Heidegger en la "Überwindung der Metaphysik", afirma:

"La imperceptible ley de la Tierra [Erde] guarda a ésta en la sobriedad que se contenta con el emerger y desaparecer de todas las cosas en el medido círculo de lo posible, al que todo se conforma y al que, no obstante, nada conoce. El abedul no va nunca más allá de aquello que para él es posible. El pueblo de las abejas habita en lo que le es posible. Sólo la voluntad humana, que por todos lados se instala en la técnica, zamarrea la Tierra estragándola, usándola abusivamente y cambiándola en artificial; la obliga a ir más allá del círculo de lo posible, tal como ha crecido en torno a ella; la obliga a aquello que ya no es lo posible y por tanto es lo imposible." ${ }^{47}$

Cualquier planteamiento libertario, como el del transhumanismo, que deposite en la tecnología esperanzas a la hora de rediseñar la condición humana o de la liberación del confinamiento terrestre no puede juzgarse más que como un esteticismo irreflexivo, por bienintencionado que parezca.

Es verdad, como argumenta Jonas ${ }^{48}$, que nuestra responsabilidad para con la existencia de humanidad futura exige como primera regla que haya hombres (imperativo de existencia: que sean), pero debe comprometernos con una idea de humanidad (imperativo de humanidad: que sea así). Mas esta última implica otra forma de responsabilidad y otra forma no moral de reciprocidad; a saber: los individuos humanos, en cuanto conviven, tienen responsabilidad por alguien y ante alguien (presente, pasado o futuro), pero, en cuanto humanum específico, siempre son responsabi- lidad de algo. Y esto es lo que exige nuestro cuidado para seguir siendo así. Pero, ¿ cómo? Jonas lo ha dejado escrito: "Exagerando cabría decir que la posibilidad de que haya responsabilidad es la responsabilidad que antecede a todo" 49 . Estamos ante un imperativo y una responsabilidad que no es no sólo moral, sino también metafísica: el futuro de la naturaleza (incluida su propia naturaleza) como conditio sine qua non es posible lo humanum.

Como animal dotado de razón y fantasía; como ser libre, el ser humano podría abandonar esa responsabilidad metafísica, esa aventura cósmica que lo ha hecho posible, y guiarse por un obrar frívolo y evitable. Podríamos echar a perder nuestro mundo o nuestra misma condición humana, pero habríamos sido unos irresponsables metafísicos: no garantizaríamos la existencia futura de seres humanos con Ethikfähigkeit, esto es, con capacidad para ser sujetos de derechos y deberes para con los demás hombres, pero también para con los demás animales y seres en general. Sólo un gnosticismo injustificado puede hacer, por tanto, que los transhumanistas defiendan la vida inteligente y no le otorguen a lo material (a la misma Tierra) más valor (o disvalor) que el de ser un confín de lo humano.

$\mathrm{Ni}$ el cuerpo, ni el planeta son impedimentos para nuestra humanidad. Son constitutivos de ella. Kant enseñó sobre los deberes para nuestro cuerpo en sus Lecciones de ética del semestre de invierno del curso 1784-1785:

"el cuerpo constituye una condición inexcusable para la vida; es imposible concebir ésta sin aquél, el cual constituye una parte de nosotros mismos y posibilita el uso de nuestra libertad." 50

Poner en peligro el cuerpo o destruirlo implica arriesgar el mismo arbitrio que nos permite aquel obrar, lo que implica una contradicción. La conservación del cuerpo, como la de la vida animal, que somos, es pues un deber supremo ${ }^{51}$, que sólo ha de ser colocado - añade Kant - en un segundo plano si conlleva vivir indignamente: bajo la tutela o arbitrio de otro ${ }^{52}$.

En la misma dirección y sentido limita Habermas en El futuro de la naturaleza humana, cualquier tipo de antropotecnia; de hecho, plantea la necesidad de una ética de la especie que exige conservar la constitución genética natural (el ser) de los humanos para mantener intactas las premisas formales de la ética del discurso ${ }^{53}$.

No hay espacio en Kant o Habermas para el dualismo ontológico cartesiano - que anida, por cierto, tras 
el gnosticismo de los transhumanistas-. La tesis de Kant suena así:

"donde yo siento, allí estoy [wo ich empfinde, da bin ich]. Estoy justamente tanto en la punta del dedo como en la cabeza. Soy el mismo que se duele de los talones y al que el corazón palpita en los afectos. Si me atormenta mi callo, experimento la impresión dolorosa no en un nervio del cerebro, sino al final de mi dedo. Ninguna experiencia me enseña que haya de pensar como distantes de mí algunas partes de mi sensación y encerrar mi yo indivisible en un pequeño lugar microscópico del cerebro para que desde allí ponga en movimiento la palanca de la máquina de mi cuerpo o llegue a ser afectado mediante la misma." ${ }^{54}$

Otro tanto cabe decir de la Tierra. Para la especie humana constituye, según, la doctrina del derecho kantiana, una posesión común (communio possesionis originaria). $\mathrm{Y}$, aunque exista un derecho de cada uno de los hombres a usarla (incluso como residencia o sede), "todos los hombres tienen el derecho a existir alli donde la naturaleza o el azar los ha colocado (al margen de su voluntad)"55. Se trata, además, de una posesión originaria, previa a todo acto jurídico, constituida por la naturaleza misma, como madre común. Resulta decisiva, en este punto, la idea de comunidad humana y, más allá, de la comunidad natural, pues en el $\$ 80$ de la Crítica del Juicio concibe, como remarcamos al comienzo, la naturaleza como una gran familia [große Familie von Geschöpfen]. Se trata de una concepción que anticipa también la más reciente hipótesis Gaia. En el Opus postumum podemos leer:

"Igual que son representadas las sustancias orgánicas como vivas, cabría representarse del mismo modo a la Tierra entera, pues los animales se alimentan mutuamente los unos y otros, como también ocurre con los vegetales respecto de aquéllos; de modo que hay que considerar a todos ellos en conjunto como formando un todo orgánico, no sólo mecánico." ${ }^{56}$

Es preciso, por tanto, limitar el alcance del antropocentrismo moral de $\mathrm{Kant}^{57}$. Reparemos, en este sentido, que el mismo filósofo en una nota de la Crítica del Juicio (§ 90) señala que, dada la íntima semejanza en la construcción de castores y hombres (esto es, del instinto y la técnica humana), estamos autorizados (por razonamiento analógico) a pensar "que los animales obran conforme a representaciones (y no son máquinas como pretende Descartes ${ }^{58}$ ) y que, al margen de su heterogeneidad específica, son idénticos a los hombres según el género (como seres vivos)" 59 , lo que, evidentemente, como apunta en las Lecciones de ética del curso 1984-85, daría contenido a la idea reciprocidad moral con ellos ${ }^{60}$; sentido a la idea de una necesaria solidaridad bioantropocósmica; fundamento la idea de justicia ecológica; y garantía a los derechos positivos de los animales y del medio ambiente.

Jonas tiene también clara esa misma reciprocidad. Ha propuesto, por ello, un nuevo imperativo moral para nuestra civilización tecnológica: obra siempre de tal modo que los efectos de las acciones sean compatibles con la permanencia de una vida humana auténtica en la Tierra; o, expresado negativamente: no poniendo en peligro las condiciones de la continuidad indefinida de la humanidad en la Tierra; o, formulado una vez más positivamente: incluyendo en nuestras elecciones actuales, como objeto también del querer, la futura integridad del hombre ${ }^{61}$. Es ésta una lección que deben aprender los transhumanistas y que Kant ya enseñó en sus clases de filosofía moral cuando defendía en público esta cabal regla de la ética de la especie:

"La regla originaria conforme a la que debo restringir la libertad se cifra en compatibilizar la conducta libre con los fines esenciales de la humanidad." ${ }^{2}$ 
1 "En la medida en que se forma su cuerpo -escribe Kant-, las facultades de su naturaleza intelectiva reciben también los grados convenientes de perfectibilidad [Vollkommenheit] y alcanzan una capacidad asentada y viril sólo cuando las fibras de sus instrumentos llegan a la solidez y duración adecuada en su formación." (Historia general de la naturaleza, III, apéndice; Ak. I, 355-356). Los textos de Kant se citan según la edición canónica de la Preussischen Akademie der Wissenschaften, Berlín, 1902-1997: Kant's gesammelte Schriften. Se hace referencia a esa edición (Ak.), seguido del volumen y página correspondiente.

2 Historia general de la naturaleza, III, apéndice; Ak. I, 364.

3 Sueños de un visionario, I, I; Ak. II, 327.

4 En Kant y las ciencias de la vida (Madrid, Biblioteca Nueva, 2008) he desarrollado una reconstrucción de la filosofía trascendental de Kant a partir del concepto de epigénesis, un concepto embriológico clave de la biología del desarrollo, que Kant eleva a rango filosófico en la misma Crítica de la razón pura (\$ 27) a hablar de la epigénesis de las categorías del entendimiento.

5 El término involutio fue introducido por Carpar F. Wolff en su polémica con e preformismo de Haller para diferenciar su concepto de "desarrollo" de la "evolutio" halleriana. Cfr. Theoria generationis, I, p. 24.

6 En este proceso continuo de emergencias que va de la physis al anthropos, pasando por la bios, juega un papel primordial el éter. Él es, según Kant, la materia o estofa primordial que llena desde el origen todo el universo macroscópico y microscópico (Allgemeine Naturgeschichte, Ak I, 306-307). En las Reflexionen zur Physik und Chemie habla de la Gebärmutter [la matriz, el útero] de todos los cuerpos y la fuente de toda cohesión (Reflexión n 44, Ak. XIV, 295), con lo que es el medio en el que acontecen todos los fenómenos físicos, químicos, y biológicos. En el Opus postumum señala, por eso Kant que debe postularse como comienzo del cosmos "una materia, que, penetrando interiormente todos los cuerpos, los mueve al mismo tiempo de modo continuo, constituyendo por ella misma un todo que, como todo cósmico subsistente y automoviente por sí internamente, sirve de base a toda otra materia móvil (...)”. "La proposición hay cuerpos físicos, presupone - escribe Kant- esta otra: hay materia cuyas fuerzas motrices y movimiento preceden en el tiempo a la producción de un cuerpo. Esta producción es, en efecto, sólo la configuración de aquella materia [etérea] y acontece por sí misma (spontaneo)." (Opus postumum, Ak. $X X I, 216$. ). Es esta una reflexión importante, porque esta espontaneidad que señala nuestro autor es, precisamente, lo que puede servir de fundamento de la autonomía de la naturaleza para producir sus propios seres sin intervención sobrenatural alguna. Podríamos decir que toda materia, en cuanto presupone la materia etérea, tiene, en virtud de actividad interna, una inagotable fuerza formativa (Bildungskraft) que permite la emergencia (Enstehung) de órdenes de realidad diferentes. En el mismo prefacio de Allgemeine Naturgeschichte und Theorie des Himmels decía (Ak., I, 230): „Gebet mir Materie, ich will euch zeigen, wie eine Welt daraus entstehen soll!" [iDádme materia y os mostraré cómo ha de emerger un Universo de ella!]. El éter, al ser un medio material fluido, elástico y sutil, perpetuamente animado de movimientos ondulatorios y vibratorios, y ocupar todo el espacio cósmico, sin dejar intersticio o vacío alguno, es capaz de producir, sin sufrir la influencia de ninguna fuerza exterior cambios de estado y materias de densidades diferentes, constituyendo así diferentes cuerpos físicos, a los que, a su vez, penetra haciendo posible sus diferentes propiedades o cambios de estado. Además, al servir de medio universal y llenarlo todo, el continuum etéreo hace posible que todo lo que hay en el universo constituya una comunidad de acción recíproca (Reflexión $\mathrm{n}^{\circ}$ 79; Ak XIV, 525).

7 Crítica del Juicio, § 80; Ak. V, 418-419.

8 Crítica del Juicio, § 65; Ak. V, 374.

9 Crítica del Juicio, § 91; Ak. V, 467-468.

10 Cfr. Prolegomenos, § 60; Ak. IV, 364.

11 Fundamentación de la metafísica de las costumbres, I; Ak. IV, 395.

12 Claro que, en tal caso, como ha sugerido Popper, ¿no habría que voltear el argumento y afirmar que si el hombre es libre, al menos en parte también ha de serlo la naturaleza, y, por consiguien- te, defender que el mundo físico (el Mundo-1 de Popper) no está tampoco causalmente cerrado, sino que es igualmente abierto? (EI universo abierto. Post scriptum a La lógica de la investigación científica, Madrid, Tecnos, 1985, vol. II, p. 149).

13 Comienzo presunto..., Ak. VIII, 114.

14 Crítica del Juicio, § 63, Ak. V, 368-369.

15 Vid., Crítica del Juicio, § 82, Ak. V, 426. Allí Kant escribe: "Si recorremos, empero, toda la naturaleza no encontramos en ella, en cuanto naturaleza, ningún ser que pueda reivindicar el privilegio de ser fin final [Endzweck] de la creación; y hasta puede demostrarse a priori que cuanto pudiera ser considerado para la naturaleza un fin último [letzte Zweck], conforme a todas las determinaciones y propiedades imaginables que se le pudieran atribuir, nunca podrá ser sin embargo, en cuanto cosa de la naturaleza, un fin final".

16 Crítica del Juicio, § 82, Ak. V, 428. El énfasis es mío.

17 Crítica del Juicio, § 63; Ak. V, 368.

18 Crítica del Juicio, § 63; Ak. V, 369.

19 Beweisgrund, Ak. II, 98-99.

20 HOTTOIS, G., El paradigma bioético, Barcelona, Anthropos, 1991, pp. 153154.

21 Antropología en sentido pragmático, Ak. VII, 322-323.

22 En Obras completas, t. IX.

23 NIETZSCHE, F., Genealogía de la moral, Madrid, Alianza, 19783, III, 9, p. 131. Como ha señalado Vattimo en Ética de la interpretación, la figura nietzscheana del ultrahombre parece aludir a las dos vías principales recorridas por las vanguardias del XIX: por un lado, el experimentalismo tecnicista, que es voluntad metafísica de forma, y, por otro, la disolución de todo dominio de la forma en nombre de un arte ya no sujeto a ideales constructivos, sino dirigido, más bien, a recorrer hasta el fondo la experiencia de la deconstrucción. (Barcelona, Paidós, 1991, p. 129). En el fondo, "Tener y querer tener más, en una palabra, crecimiento; eso es la vida misma" (La voluntad de poder, n. 125). 
Toda mera conservación de la vida es ya declinación de la vida.

24 NIETZSCHE, F., Genealogía de la moral, II, 16, p. 97. Énfasis mío.

25 KURZWEIL, R., The Singularity is Near: When Humans Transcend Biology. New York: Viking, 2005, p. 383.

26 Vid. BOSTROM, N., "In Defence of Posthuman Dignity", en: Bioethics, Vol. 19/3 (2005), pp. 202-214; “Dignity and enhancement", en: The President Council on Bioethics, Human Dignity and Bioethics: Essays Commissioned by the President's Council on Bioethics, Washington, DC: U.S. Government Printing Office, 2008.

27 SLOTERDIJK, P., Normas para el parque humano, Madrid, Siruela, 2003, p. 70.

28 NIETZSCHE, F., Anticristo. Madrid, Alianza, 2006, pp. 32-35

29 Sloterdijk reconoce la importancia de la antropología plessneriana (expuesta, por ejemplo, en Die Stufen des Organischen und der Mensch. Einleitung in die philosophische Anthropologie", 1928 y Macht und menschliche Natur. Ein Versuch zur Anthropologie der geschichtlichen Weltansicht, 1931), pues, al afirmar la importancia conceptual de la artificialidad natural y la mediación sociohistórica para la determinación de la idea de humanidad, concede centralidad a la noción de la auto-extrañamiento (Selbstentfremdung). El hombre, para Plessner, no debe emanciparse y buscar una identidad fuera de él, porque en realidad la Unheimlichkeit coincide con la condición errática de un ser naturalmente artificial. Véase: SLOTERDIJK, Nicht gerettet. Versuche nach Heidegger, Frankfurt, 2001, pp. 82 y sigs. También: Extrañamiento del Mundo; (trad. Eduardo Gil Bera); Valencia, Pre-Textos; 1998 [publicada en alemán en 1993].

30 BOSTROM, N., "The Future of Human Evolution", en: Death and Anti-Death: Two Hundred Years After Kant, Fifty Years After Turing, ed. Charles Tandy (Palo Alto, California, Ria University Press, 2004, pp. 339-371).

31 BECK, U., La sociedad del riesgo, BarceIona, Paidós, 1998, p. 25.

32 El informe más completo sobre la EEB puede encontrarse en The ESB Inquiri: The Report, disponible en: http://www. bseinquiry.gov.uk/report/index.htm.
33 Journal of Virology, vol.72, №. 9, pp.7367-7373.

34 WUETHRICH, B., "Infectious Disease: Chasing the Fickle Swine Flu", en: Science, vol. 299/5612 (2003), pp. 15021505.

35 № 44 (2007), pp. 1084-1088. Claro que, sobre este punto no faltan ya informes sobre la utilización en la Universidad de Cambridge y en el Instituto Roslin en Escocia de la ingeniería genética en pollos para producir aves transgénicas resistentes a las cepas letales del virus H5N1.

36 BECK, U., Op. cit., p. 217.

37 ECHEVERRIA, J., "Tecnociencia, riesgo e incertidumbre: el caso de las nanotecnologías", en: MOYA, E. (ed.), Pensar el presente. Incertidumbre humana y riesgos globales, Madrid, Biblioteca Nueva, 2009, p. 64.

38 JONAS, H., Memorias, Oviedo, Losada, 2005, p. 352.

39 JONAS, J., El principio vida. Hacia una biología filosófica, Madrid, Trotta, 2000, p. 129.

40 JONAS, H., El principio de responsabilidad. Ensayo de una ética para una civilización ontológica, Barcelona, Herder, 1995, pp. 133-134.

41 JONAS, J., El principio vida, p. 131

42 Para Kant, en los mecanismos (cuerpos físicos) tan sólo podemos observar simple composición, mientras que en los organismos o cuerpos vivos, encontramos organización y autoorganización, esto es, (1) Algo en lo que cada parte (según su existencia y forma) sólo existe para todas las otras y por motivo del todo. (2) Algo que posee Einheit. (3) Algo que en su crecimiento es capaz de producirse, generarse [hervorbringen] a sí mismo como individuo, organizando para sí otros elementos (órganos) y la misma materia inerte, de acuerdo con un orden que permanece, en lo esencial inalterado. (4) Algo que es capaz de reproducirse (fortpflanzen) a sí mismo según la especie, en la cual él opera, por un lado, como efecto y, por otro, como causa. (5) Algo que con otros individuos está ordenado en Gattungen, especies, cuya unidad "ist nichts anders, als die Einheit der zeugenden Kraft". Son cualidades que Kant sintetiza en la idea fin natural (Naturzweck). Véase la Crítica del Juicio, § 65; Ak. V, 373-374. Cfr. WE-
BER, A. y VARELA, F., "Life alter Kant. Natural purposes and the autopoietic foundations of biological individuality", en: Phenomenology and Cognitive Sciences, 1:97 (2002), pp. 97-125. Cfr., también, mi Kant y las ciencias de la vida, especialmente, capítulo 2: "La trama de la vida: el concepto de autoorganización", pp. 85-138.

43 Sobre el uso de principios teleológicos en Filosofía, Ak. VIII, 79.

44 Crítica del Juicio, § 82, Ak. V, 425. Las cursivas son mías.

45 Véase, CORTINA, A., Las fronteras de la persona. El valor de los animales, la dignidad de los humanos, Madrid, Taurus, 2009.

46 JONAS, H., El principio de responsabilidad, p. 38.

47 HEIDEGGER, M., Conferencias y artícuIos, Barcelona; serbal, 2001, p. 72. Traducción de Barjau con modificaciones.

48 JONAS, H., El principio de responsabilidad, pp. 88-89.

49 JONAS, H., El principio de responsabilidad, p. 174.

50 Moralphilosophie Collins, Ak. XXII/1, 369.

51 Véase también el comienzo de la "Doctrina de la virtud" en la Metafísica de las costumbres, Ak. VI, 421.

52 Moralphilosophie Collins, Ak. XXII/1, 377-378.

53 HABERMAS, J. El futuro de la naturaleza humana. ¿Hacia una eugenesia liberal?, Barcelona, Paidós, 2002, p. 68: “Con las intervenciones genéticas sobre humanos, el dominio de la naturaleza se convierte en un acto de autoinvestidura de poderes que modifica nuestra autocomprensión ética de la especie y podría afectar a condiciones necesarias para una guía autónoma de la vida y una comprensión universalista de la moral". En la p. 118, escribe: "Hay una idea regulativa para trazar una frontera, un criterio que, aun necesitado de interpretación, no es en principio impugnable: todas las intervenciones terapéuticas, también las prenatales, tienen que depender de un consenso, al menos puesto contrafácticamente, con el posible afectado mismo". 
54 Sueños de un visionario, I, 1; Ak. II, 324325.

55 Metafísica de las costumbres, I, § 13; Ak. VI, 262.

56 (Ak. XXII, 276).

57 De él ha escrito sin reservas Maximiliano Hernández ("Límites y perspectivas del antropocentrismo moral de Kant de cara a una ética medioambiental", en: GARCÍA GOMEZ-HERAS, J.M., Ética del medio ambiente, Madrid, Tecnos, 1997, pp. 252-261.

58 Descartes defendió que no se da ninguna diferencia esencial entre el animal y la máquina, sino tan sólo "secundum, magis et minus". "Explico - decía- todos los movimientos exteriores que acompañan en nosotros al sentimiento del dolor, los cuales se encuentran en las bestias, y no el dolor mismo" (AT., III, 85.). En las bestias, como en los vegetales se producen simples movimientos externos que acompañan a la estimulación. Son movimientos reflejos causados por el flujo de espíritus animales que, una vez excitados por los estímulos, entran en acción. A su impulso, los animales huirán y emitirán sonidos. Pero no sienten, en un sentido propio, pues toda sensación va unida a conciencia, a pensamiento. Malebranche, por ello, al oír los aullidos de una perra preñada que era golpeada, sólo exclamaba: "iEs una máquina! ¡No siente nada!". Para él, como para Descartes, los sonidos y conductas de los animales no expresan dolor. Vid. A-T., XI, 520.
59 Crítica del Juicio, § 90; Ak. V, 464 nota. En la Moralphilosophie Collins (XXVII/1, 345) y en la Praktische Philosophie Her$\operatorname{der}(\mathrm{XXVII} / 1,85)$ había mantenido que "En los animales las inclinaciones ya están determinadas por principios que se imponen subjetivamente".

60 KANT, I., Moralphilosophie Collins, XX$\mathrm{VII} / 1,459$.

61 JONAS, H., El principio de responsabilidad, pp. 39-41.

62 KANT, I., Moralphilosophie Collins, XX$\mathrm{VII} / 1,345$ 